\title{
A MORPHOMETRIC STUDY OF UPPER END OF FEMUR AND ITS IMPLICATIONS IN HEMIARTHROPLASTY
}

\author{
Durga. ${ }^{* 1}$, K. R. Dakshayani ${ }^{2}$. \\ ${ }^{* 1}$ Postgraduate, Department of Anatomy, Mysore Medical College and Research Institute, Mysore, \\ Karnataka, India. \\ ${ }^{2}$ Principal, Professor and Head, Department of Anatomy, Mysore Medical College and Research \\ Institute, Mysore, Karnataka, India.
}

\section{ABSTRACT}

Introduction: Hemiarthroplasty of hip is very common now-a-days in fracture neck of femur. So there is always need of population specific data for making best fit prosthesis to reduce complications following the procedure.

Objectives: To measure Femoral Head Diameter, Femoral Neck Length, Femoral Neck Diameter, Femoral Neck Thickness and Cervico- Diaphyseal Angle. To find the correlation between each parameter.

Materials and method: 100 dry femur, required for the study, were collected from the Department of Anatomy, Mysore Medical College, Mysore. Measurements were obtained using a digital vernier calliper, a ruler and a protractor.

Results: Mean value of Femoral Head Diameter was similar to other Indian studies. Mean value of CervicoDiaphyseal Angle varied as that of western studies. The values of Femoral Head Diameter show high correlation with the values of Femoral Neck Diameter, Length and Thickness.

Conclusion: The regional variations noted in this study will help designing prosthesis of appropriate head, neck and stem size, thus reducing the failure rates in hemiarthroplasty.

KEY WORDS: Upper end of Femur, Hemiarthroplasty, Morphometry of Femur.

Address for Correspondence: Dr. Durga P, Postgraduate, Department of Anatomy, Mysore Medical College and Research Institute, Mysore, Karnataka, India. E-Mail: durgapon@gmail.com

Access this Article online

Quick Response code

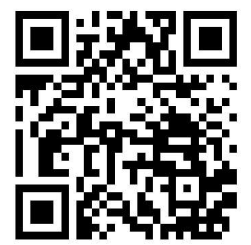

DOI: $10.16965 /$ ijar.2018.403

\section{Journal Information}

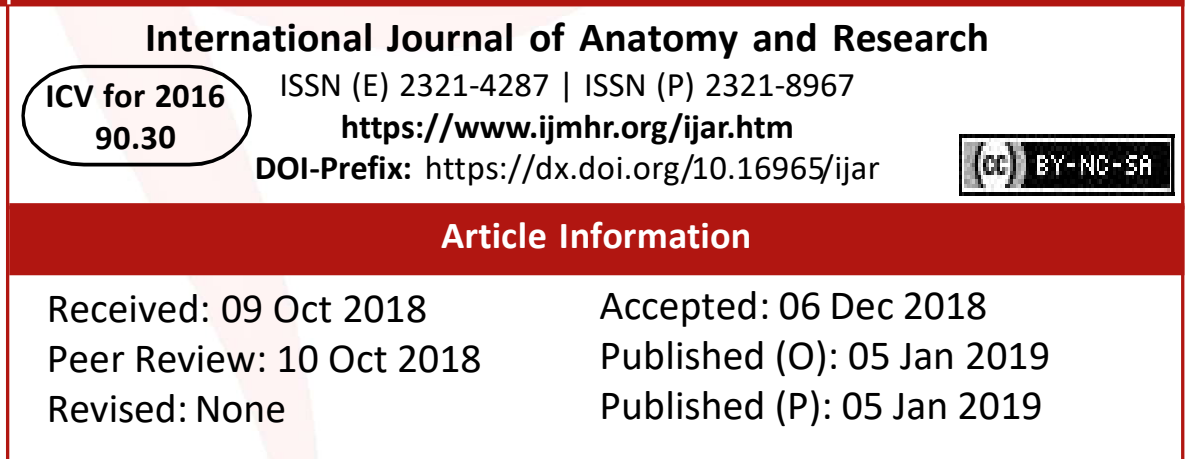

\section{INTRODUCTION}

The femur is the largest and strongest bone in the body and the structure of its proximal portion allows the leg to move in three dimensions relative to the torso, thus serving as a linchpin of human mobility [1].

Intertrochanteric fractures with severe displacement and comminution are common in elderly patients. These patients have a poor bone quality and the fractures are often associated with complications such as non union, metal failure and femoral head perforation [2,3]. Femoral neck fractures involve the narrow neck between the round head of the femur and the shaft [4].

To allow an earlier Post-operative weight-bearing and a rapid rehabilitation and to avoid excessive collapse at the fracture site, some surgeons have recommended prosthetic replacements for the treatment of unstable intertrochanteric fractures [5-7]. Studies by Rogmark et al.,[8] and Roden et al.,[9]showed complications of non-union, avascular necrosis and a high rate 
(30-40\%) of reoperation following internal fixation and superior function after primary hemiarthroplasty which eliminates these complications as the femoral head and neck is replaced by metallic implant[10]. Instability and dislocation after total hip arthroplasty are the most common causes of revisions and major complications for failure of inserted prostheses, leading to a reduction in quality of life. Because the use of artificial femoral head sizes smaller than patient's own size is the important cause for dislocation, the use of large femoral head have increased. Femoral head sizes greater than $32 \mathrm{~mm}$ offer multiple advantages in physical function and activity levels of patients by improving hip stability, decreasing dislocation rate and increasing range of motion. However, various concerns are encountered including wear debris generation at the trunnionbore interface and increases in frictional torque and stress over the component-bone interface when using larger head sizes[11] Variations in hip morphology are also of critical interest to surgical planning where the ability to take hip morphology into account on a patient specific basis is crucial for success in choosing designs of implants and other structures used for hip replacements and augmentations of hip stability[12]. Use of western implants in Indians increases the chance of implant failure significantly leading to malunion, non-union and avascular necrosis[13]. As the environment plays an important role in the development, the regional variation of the femur bone is influenced by geographical area, sex, stature, and heredity. The knowledge of variations in the parameters of dry femora will help the orthopedicians and also assist prosthetists to design a suitable prosthesis for restoration of normal neck shaft angle[14].

Aim: To measure the morphometric parameters of upper end of femur- Femoral Head Diameter (FHD),Femoral Neck Diameter (FND), Femoral Neck Length (FNL), Femoral Neck Thickness (FNT), Cervico-Diaphyseal Angle (CDA).To compare their values on right and left side.

\section{MATERIALS AND METHODS}

For the prospective morphometric study, 100 dry femurs from human cadavers of both sexes were obtained from the Department of Anatomy, Mysore Medical College and Research Institute,Mysore from May 2017 to December 2017. Out of 100 dry femurs, 50 were of right side and 50 were of left side. Sample size selection was done with reference to the research paper by Minakshi Verma et al., on the Morphometry of Proximal Femur in Indian Population [15]. ( $N=100, \alpha=5 \%$, power $80 \%)$. Bones with visible osseous pathologies like tumours, deformities, fractures, trauma were excluded. Morphometric parameters of upper end of femur were measured manually by using anthropometric instruments like ruler, goniometer and digital calliper.FHD(Femoral Head Diameter) was the distance in a straight line between the upper end to the lower end of the femoral head in cranio caudal axis [Figure-1].FNL(Femoral Neck Length) was the distance between the inferior region of base of femoral head and the lower end of intertrochanteric line [Figure-2]. FNT(Femoral Neck Thickness) was thickness of neck of femur in antero posterior axis [Figure3]. FND(Femoral Neck Diameter) was the distance in a straight line from upper end to the lower end of the anatomical neck of femur in craniocaudal direction [Figure-4], and Cervico Diaphyseal Angle (CDA) was the angle between the line joining the center of head of femur and the midpoint of Intertrochantric line (Femur Neck Axis) and vertical line from the tip of greater trochanter (Femur Shaft Axis) [Figure-5].

Statistical Analysis: Data was tabulated and reported as mean \pm Standard deviation. Spearmans correlation was used to analyse the relationship between all parameters[TABLE-5].

\section{RESULTS}

Mean value of the parameters are as follows: Femoral Head Diameter: $42.33 \pm 3.8 \mathrm{~mm}$ (total), $42.23 \pm 3.3 \mathrm{~mm}$ (right), $42.43 \pm 4.2 \mathrm{~mm}$ (left); Femoral Neck Length: $33.9 \pm 6.7 \mathrm{~mm}$ (total), 35.69 $\pm 7 \mathrm{~mm}$ (right), $32.16 \pm 5.9 \mathrm{~mm}$ (left); Femoral Neck Diameter: $30.43+3.7 \mathrm{~mm}$ (total), 30.22 $\pm 3.4 \mathrm{~mm}$ (right), $30.65 \pm 3.9 \mathrm{~mm}$ (left); Femoral Neck Thickness: $25.64 \pm 3.5 \mathrm{~mm}$ (total), $25.13 \pm 2.9 \mathrm{~mm}$ (right), $26.15 \pm 3.9 \mathrm{~mm}$ (left); Cervico - Diaphyseal Angle: $117.6 p \pm 8.5 p$ (total) ,116.84p $\pm 8.07 p$ (right), $118.52 p \pm 8.9 p$ (left) . Femoral Head Diameter values are 
Durga. P, K. R. Dakshayani. A MORPHOMETRIC STUDY OF UPPER END OF FEMUR AND ITS IMPLICATIONS IN HEMIARTHROPLASTY.

classified as follows: $<37 \mathrm{~mm}(7 \%) ; 37.1-$ $39 \mathrm{~mm}(15 \%) ; 39.1-41 \mathrm{~mm}(12 \%) ; 41.1-43 \mathrm{~mm}$ (23\%); 43.1- 45mm(17\%); 45.1- 47mm (15\%); 47.1- $49 \mathrm{~mm}(7 \%) ;>49 \mathrm{~mm}(4 \%)$. All these values were tabulated in [TABLE-1].

Table 1: Morphometric parameters of upper end of femur.

\begin{tabular}{|c|c|c|c|}
\hline Parameters & $\begin{array}{c}\text { Mean average } \\
\text { total }\end{array}$ & $\begin{array}{c}\text { Mean average } \\
\text { right }\end{array}$ & $\begin{array}{c}\text { Mean average } \\
\text { left }\end{array}$ \\
\hline Femoral head diameter & $42.33 \pm 3.8 \mathrm{~mm}$ & $42.23 \pm 3.3 \mathrm{~mm}$ & $42.43 \pm 4.2 \mathrm{~mm}$ \\
\hline Femoral neck length & $33.9 \pm 6.7 \mathrm{~mm}$ & $35.69 \pm 7 \mathrm{~mm}$ & $32.16 \pm 5.9 \mathrm{~mm}$ \\
\hline Femoral neck diameter & $30.43 \pm 3.7 \mathrm{~mm}$ & $30.22 \pm 3.4 \mathrm{~mm}$ & $30.65 \pm 3.9 \mathrm{~mm}$ \\
\hline Femoral neck thickness & $25.64 \pm 3.5 \mathrm{~mm}$ & $25.13 \pm 2.9 \mathrm{~mm}$ & $26.15 \pm 3.9 \mathrm{~mm}$ \\
\hline Cervico- diaphyseal angle & $117.6^{\circ} \pm 8.5^{\circ}$ & $116.84^{\circ} \pm 8.07^{0}$ & $118.52^{\circ} \pm 8.9^{\circ}$ \\
\hline
\end{tabular}

\section{DISCUSSION}

Femoral head diameters were classified into various ranges and frequency in each range was noted and tabulated [TABLE-2]. High frequency $(23 \%)$ was found in the range of $41.1-43 \mathrm{~mm}$. In the present study, parameters were calculated manually using anthropometric instruments.Other methods used to measure the parameters are shown in[TABLE-3].The parameters of present study are compared with those of previous studies.The mean femoral head diameter is $42.33+3.8 \mathrm{~mm}$ which is similar to the study of Minakshi verma et al , New Delhi, India [15]. The mean Cervico-diaphyseal angle is $117.6^{\circ}$, which is different from the values of previous studies, tabulated in[TABLE- 4].There is high correlation noted in the values of femoral head diameter with femoral neck length , diameter and thickness [TABLE- 5].

Table 2: Distribution of Femoral Head Diameters.

\begin{tabular}{|c|c|}
\hline Range & Frequency \\
\hline$<37 \mathrm{~mm}$ & $7 \%$ \\
\hline $37.1-39 \mathrm{~mm}$ & $15 \%$ \\
\hline $39.1-41 \mathrm{~mm}$ & $12 \%$ \\
\hline $41.1-43 \mathrm{~mm}$ & $23 \%$ \\
\hline $43.1-45 \mathrm{~mm}$ & $17 \%$ \\
\hline $45.1-47 \mathrm{~mm}$ & $15 \%$ \\
\hline $47.1-49 \mathrm{~mm}$ & $7 \%$ \\
\hline$>49 \mathrm{~mm}$ & $4 \%$ \\
\hline
\end{tabular}

Table 3: Various methods of measurements.

\begin{tabular}{|l|l|}
\hline \multicolumn{1}{|c|}{ Study } & \multicolumn{1}{c|}{ Method } \\
\hline Minakshi verma etal - (New Delhi,India) & Digital photographs with imagej software [15] \\
\hline Ho jung cho etal - (Korea) & Automated geometric computation program using 3d models [26] \\
\hline De sousa eetal - (Brazill) & Radiographic measurements using xrays [27] \\
\hline Zaki et al (Egypt) & Radiological measurements using ctimages[25] \\
\hline
\end{tabular}

Table 4: Comparison of parameters of present study with previous studies.

\begin{tabular}{|l|c|c|c|c|c|}
\hline \multicolumn{1}{|c|}{ Parameters/Study } & FHD & FNL & FND & FNT & CDA \\
\hline Present Study & $42.33 \mathrm{~mm}$ & $33.9 \mathrm{~mm}$ & $30.43 \mathrm{~mm}$ & $25.64 \mathrm{~mm}$ & $117.6^{0}$ \\
\hline Minakshi verma et al, New Delhi [15] & $42.31 \mathrm{~mm}$ & $44.75 \mathrm{~mm}$ & $32.98 \mathrm{~mm}$ & $24.01 \mathrm{~mm}$ & $128.9^{\circ}$ \\
\hline Aparna gullapalli et al, Andhra Pradesh [28] & - & - & - & - & $121^{\circ}$ \\
\hline Ravi G.0,et al, South India [12] & - & $36.3 \mathrm{~mm}$ & - & - & $136.8^{\circ}$ \\
\hline $\begin{array}{l}\text { Prabha nand chaudhary et al, North } \\
\text { Karnataka[14] }\end{array}$ & - & $28.8 \mathrm{~mm}$ & - & - & $127.21^{\circ}$ \\
\hline De sousa et al, Brazil [27] & - & $30.3 \mathrm{~mm}$ & $46.75 \mathrm{~mm}$ & $30.95 \mathrm{~mm}$ & $131.9^{\circ}$ \\
\hline
\end{tabular}

Table 5: Correlation of one parameter with other parameters.

\begin{tabular}{|c|c|c|c|c|c|c|}
\hline \multicolumn{7}{|c|}{ Spearman's rho Correlations } \\
\hline \multirow{4}{*}{ FHD } & FHD & FNL & FND & FNT & CDA \\
\cline { 2 - 7 } & Correlation Coefficient & 1 & $.278^{* *}$ & $.841^{* *}$ & $.782^{* *}$ & -0.037 \\
\cline { 2 - 7 } & Sig. (2-tailed) &. & 0.004 & 0 & 0 & 0.71 \\
\hline \multirow{4}{*}{ FNL N } & 103 & 103 & 103 & 103 & 103 \\
\cline { 2 - 8 } & Correlation Coefficient & $.278^{* *}$ & 1 & $.302^{* *}$ & $.235^{*}$ & -0.004 \\
\cline { 2 - 8 } & Sig. (2-tailed) & 0.004 &. & 0.002 & 0.017 & 0.967 \\
\cline { 2 - 8 } FND & N & 103 & 103 & 103 & 103 & 103 \\
\cline { 2 - 8 } & Correlation Coefficient & $.841^{* *}$ & $.302^{* *}$ & 1 & $.838^{* *}$ & -0.103 \\
\cline { 2 - 8 } & Sig. (2-tailed) & 0 & 0.002 &. & 0 & 0.298 \\
\hline \multirow{3}{*}{ FNT } & N & 103 & 103 & 103 & 103 & 103 \\
\cline { 2 - 8 } & Correlation Coefficient & $.782^{* *}$ & $.235^{*}$ & $.838^{* *}$ & 1 & -0.089 \\
\cline { 2 - 8 } & Sig. (2-tailed) & 0 & 0.017 & 0 &. & 0.371 \\
\cline { 2 - 8 } & $\mathrm{N}$ & 103 & 103 & 103 & 103 & 103 \\
\hline \multirow{3}{*}{ CDA } & Correlation Coefficient & -0.037 & -0.004 & -0.103 & -0.089 & 1 \\
\cline { 2 - 8 } & Sig. (2-tailed) & 0.71 & 0.967 & 0.298 & 0.371 &. \\
\cline { 2 - 8 } & $\mathrm{N}$ & 103 & 103 & 103 & 103 & 103 \\
\hline
\end{tabular}

**. Correlation is significant at the 0.01 level (2-tailed).

*. Correlation is significant at the 0.05 level (2-tailed).

Limitations: Study was done on dry bones. Hence right and left bones are not from same individual. Gender and Age could not be taken into account.

\section{CONCLUSION}

Intertrochanteric fractures with severe displacement and comminution are common in elderly patients. These patients have a poor bone quality and the fractures are often associated with complications such as non union, metal failure and femoral head perforation $[16,17]$.

To allow an earlier Post-operative weight-bearing and a rapid rehabilitation and to avoid excessive collapse at the fracture site, surgeons have recommended prosthetic replacements for the treatment of unstable intertrochanteric fractures [18-20]. Numerous studies have also shown that there is increase in the rate of intra operativecomplication in the event of using mismatched implants especially over size 
implants[21]. Commercially available hip prostheses are made based on European data $[22,23]$. callipers and ring gauge measurements are more reliable than the $\mathrm{CT}$ and X-ray methods for measurement of femoral head diameter in hemiarthroplasty[24].The values in present study shows variations with other studies from different regions. Hence region specific data of present study helps orthopedicians in selecting appropriate prosthesis, to reduce postoperative failure of prosthesis in hemiarthroplasty.

\section{Conflicts of Interests: None}

\section{REFERENCES}

[1]. Susan Standring, Gray's Anatomy, The Anatomical basis of clinical practice, 40 edition, Elsevier Churchill Livingstone, London. 2008; 1360-13.

[2]. Haidukewych GJ, Israel TA, Berry DJ. Reverse obliquity fractures of the intertrochanteric region of the femur. J Bone Joint Surg Am. 2001; 83(5):643- 50.

[3]. Kang SY, Lee EW, Kang KS, et al. Mode of fixation failures of dynamic hip screw with TSP in the treatment of unstable proximal femur fracture: biomechanical analysis and a report of 3 cases. J Korean Orthop Assoc. 2006; 41(1):176- 80.

[4]. Subtrochanteric femur fractures. Orthopaedia Main. In: Orthopaedia - Collaborative Orthopaedic Knowledgebase. Created Jan 27, 2008 17:18. Last modified Nov 22, 2009 20:14 ver.10.

[5]. Broos PL, Rommens PM, Geens VR, Stappaerts KH. Pertrochanteric fractures in the elderly. Is the Belgian VDP prosthesis the best treatment for unstable fractures with severe comminution. Acta Chir Belg.1991; 91:242-49.

[6]. Harwin SF, Stern RE, Kulick RG. Primary BatemanLeinbach bipolar prosthetic replacement of the hip in the treatment of unstable intertrochanteric fractures in the elderly. Orthopedics. 1990; 13:113136.

[7]. Green S, Moore T, Proano F. Bipolar prosthetic replacement for the management of unstable intertrochanteric hip fractures in the elderly. Clin Orthop Relat Res. 1987; 224:169-77.

[8]. Rogmark C, Carlsson A, Johnell O, Sernbo I. Primary hemiarthroplasty in old patients with displaced femoral neck fracture: A 1-year follows-up of 103 patients aged 80 years or more. Acta Orthop Scand. 2002;73:605-10. [PubMed]

[9]. Roden M, Schon M, Freden H. Treatment of displaced femoral neck fractures: A randomized minimum 5year follow-up study of screws and bipolar hemiprosthesis in 100 patients. Acta Orthop Scand. 2003;74:42-4. [PubMed]

[10].Parker MJ, Khan RJ, Crawford J, Pryor GA. Hemiarthroplasty versus internal fixation for displaced intracapsular hip fractures in the elderly. A randomized trial of 455 patients. J Bone Joint Surg Br. 2002;84:1150-5. [PubMed]

[11]. Myung-Rae Cho et al. Current Concepts of Using Large Femoral Heads in THA. Hip Pelvis 2016;28(3): 134141.

[12]. Ravi G.O, Shaik Hussain Saheb, Abraham Ratna Joseph N. A Morphometric Study of Femur and Its Clinical Importance. Int J Intg Med Sci 2016;3(7):34144. ISSN 2394 - 4137

[13]. D Ravichandran et al, Proximal femoral geometry in Indians and its clinical importance. J.Anat.Soc.India 2011;60(1):6-12.

[14]. Chaudhary PN, Shirol VS, Virupaxi RD. A morphometric study of femoral length, anterior neck length, and neck-shaft angle in dry femora: A cross-sectional study. Indian J Health Sci Biomed Res 2017;10:331-4.

[15]. Minakshi Verma et al., Morphometry of Proximal Femur in Indian Population. Journal of Clinical and Diagnostic Research. 2017;11(2): AC01-AC04.

[16]. Haidukewych GJ, Israel TA, Berry DJ. Reverse obliquity fractures of the intertrochanteric region of the femur. J Bone Joint Surg Am. 2001; 83(5):643- 50.

[17]. Kang SY, Lee EW, Kang KS, et al. Mode of fixation failures of dynamic hip screw with TSP in the treatment of unstable proximal femur fracture: biomechanical analysis and a report of 3 cases. J Korean Orthop Assoc. 2006; 41(1):176- 80.

[18]. Broos PL, Rommens PM, Geens VR, Stappaerts KH. Pertrochanteric fractures in the elderly. Is the Belgian VDP prosthesis the best treatment for unstable fractures with severe comminution. Acta Chir Belg.1991;91:242-49.

[19]. Harwin SF, Stern RE, Kulick RG."Primary BatemanLeinbach bipolar prosthetic replacement of the hip in the treatment of unstable intertrochanteric fractures in the elderly". Orthopedics. 1990; 13:113136.

[20] Green S, Moore T, Proano F."Bipolar prosthetic replacement for the management of unstable intertrochanteric hip fractures in the elderly". Clin Orthop Relat Res.1987; 224:169-77

[21]. Leung K, Procter P, Robioneck B, Behrens K."Geometric mismatch of the gamma nail to the Chinese femur". Clin Orthop 1996;323:42-8.

[22]. Hushmann O, Rubin PJ, Leyvraz PF, De Roguin B, Argenson JN. Morphology of the proximal femur: a three dimensional radiographic analysis. Journal of bone and Joint Surgery B. 1992; 74(1): 28-32.

[23]. Ahmad M, Nanda R, Bajwa AS, Couto JC, Green S, Hui AC. Three Dimensional morphology of the proximal femur. J Arthroplasty. 1997;12(4):444- 50.

[24]. Meuru Athapattu et al. Biomechanical Measurement of the femoral head diameter at hemiarthroplasty of the hip. Procedia Technology 2014;17:217-222.

[25]. Zaki M, Shona S, Sayed W, Ghada A. The Proximal Femur in Egyptian (Morphometric and Radiological Study). Anat Physiol 2017;7:253. doi:10.4172/ 2161-0940.1000253. 
[26]. Ho-Jung Cho et al, Morphometric Evaluation of Korean Femurs by Geometric Computation: Comparisons of the Sex and the Population, BioMed Research International, Volume 2015, Article ID 730538, 9pages, http://dx.doi.org/10.1155/2015/730538

[27]. De Sousa, E et al,Morphometric study of the proximal femur extremity in Brazilians. Int. J. Morphol., $2012 ; 28(3): 835-840$.
[28]. Aparna Gullapalli et al, Morphometric study of femoral neck shaft angle and its clinical significance, International Journal of Anatomy and Research2017;5(3.2):4261-4264.

How to cite this article:

Durga. P, K. R. Dakshayani. A MORPHOMETRIC STUDY OF UPPER END OF FEMUR AND ITS IMPLICATIONS IN HEMIARTHROPLASTY. Int J Anat Res 2019;7(1.1):6045-6049. DOI: 10.16965/ijar.2018.403 